\title{
THE
}

\section{A Tribute to the Mind, Methodology and Mentoring of Wayne Velicer}

Lisa L. Harlow

University of Rhode Island, Iharlow@uri.edu

Leona Aiken

A. Nayena Blankson

Gwyneth M. Boodoo

Leslie A. D. Brick

Follow this and additional works at: https://digitalcommons.uri.edu/psy_facpubs

\section{The University of Rhode Island Faculty have made this article openly available.}

Please let us know how Open Access to this research benefits you.

This is a pre-publication author manuscript of the final, published article.

Terms of Use

This article is made available under the terms and conditions applicable towards Open Access Policy Articles, as set forth in our Terms of Use.

\section{Citation/Publisher Attribution}

Harlow, L. L., Aiken, L., Blankson, A. N., Boodoo, G. M., Brick, L. A. D., Collins, L. M., Cumming, G., Fava, J., Goodwin, M. S., Hoeppner, B., MacKinnon, D. P., Molenaar, P. C. M., Rodgers, J. L., Rossi, J. S., Scott, A., Steiger, J. H., \& West, S. G. (2020, in press). A tribute to the mind, methodology and mentoring of Wayne Velicer. Multivariate Behavioral Research. In press.

Available at: https://doi.org/10.1080/00273171.2020.1729083 


\section{Authors}

Lisa L. Harlow, Leona Aiken, A. Nayena Blankson, Gwyneth M. Boodoo, Leslie A. D. Brick, Linda M. Collins, Geoff Cumming, Joseph L. Fava, Matthew S. Goodwin, Bettina B. Hoeppner, David P. MacKinnon, Peter C. M. Molenaar, Joseph Lee Rodgers, J S. Rossi, Allie Scott, James H. Steiger, and Stephen G. West 
This is not the version of record but is a preprint for Harlow, L. L., Aiken, L., Blankson, A. N., Boodoo, G. M., Brick, L. A. D., Collins, L. M., Cumming, G., Fava, J., Goodwin, M. S., Hoeppner, B., MacKinnon, D. P., Molenaar, P. C. M., Rodgers, J. L., Rossi, J. S., Scott, A., Steiger, J. H., \& West, S. G. (2020, in press). A tribute to the mind, methodology and mentoring of Wayne Velicer. Multivariate Behavioral Research.

(DOI:10.1080/00273171.2020.1729083).

Submitted to: Multivariate Behavioral Research, August 17, 2019

Accepted for publication in Multivariate Behavioral Research, January 14, 2020

Published online, February 20, 2020

Running Head: MIND, METHODOLOGY AND MEMORIES OF WAYNE VELICER

\section{A Tribute to the Mind, Methodology and Mentoring of Wayne Velicer}

Lisa L. Harlow ${ }^{1}$, Leona Aiken², A. Nayena Blankson ${ }^{3}$, Gwyneth M. Boodoo ${ }^{4}$, Leslie Ann D. Brick $^{5}$, Linda M. Collins ${ }^{6}$, Geoff Cumming ${ }^{7}$, Joseph L. Fava ${ }^{8}$, Matthew S. Goodwin ${ }^{9}$, Bettina B. Hoeppner $^{10}$, David P. MacKinnon ${ }^{2}$, Peter C. M. Molenaar ${ }^{6}$, Joseph Lee Rodgers ${ }^{11}$, Joseph S. Rossi $^{1}$, Allie Scott ${ }^{12}$, James H. Steiger ${ }^{11}$, \& Stephen G. West ${ }^{2}$. After the first author, co-authors contributed equally and are alphabetized by last name.

Note. Affiliations: ${ }^{1}$ University of Rhode Island, ${ }^{2}$ Arizona State University, ${ }^{3}$ Spelman College, ${ }^{4}$ GMB Enterprises, ${ }^{5}$ Warren Alpert Medical School of Brown University, ${ }^{6}$ Pennsylvania State University, ${ }^{7}$ LaTrobe University, ${ }^{8}$ The Miriam Hospital, Lifespan, RI; ${ }^{9}$ Northeastern University,

${ }^{10}$ Massachusetts General Hospital, Harvard Medical School, ${ }^{11}$ Vanderbilt University, and ${ }^{12}$ New York State Department of Health.

\section{Acknowledgements}

Thank you for partial support from Grant G20RR030883 from the National Institutes of Health, PI: D. H. DeHayes. Thanks, are also extended to Wayne's family and to the students, faculty and staff at the University of Rhode Island Department of Psychology and Cancer Prevention Research Center, and to all others who knew and spent time with our dear colleague and friend, Wayne Velicer.

Correspondence should be addressed to: Lisa L. Harlow, Department of Psychology, Chafee Hall, Flagg Rd., University of Rhode Island, Kingston, RI 02881-0808, 1harlow@uri.edu, ORCID: Lisa L. Harlow http://orcid.org/0000-0001-8001-4178 


\section{A Tribute to the Mind, Methodology and Mentoring of Wayne Velicer}

\section{(250-word) Abstract}

Wayne Velicer is remembered for a mind where mathematical concepts and calculations intrigued him, behavioral science beckoned him, and people fascinated him. Born in Green Bay, Wisconsin on March 4, 1944, he was raised on a farm, although early influences extended far beyond that beginning. His Mathematics BS and Psychology minor at Wisconsin State University in Oshkosh, and his $\mathrm{PhD}$ in Quantitative Psychology from Purdue led him to a fruitful and far-reaching career. He was honored several times as a high-impact author, was a renowned scholar in quantitative and health psychology, and had more than 300 scholarly publications and $54,000+$ citations of his work, advancing the arenas of quantitative methodology and behavioral health. In his methodological work, Velicer sought out ways to measure, synthesize, categorize, and assess people and constructs across behaviors and time, largely through principal components analysis, time series, and cluster analysis. Further, he and several colleagues developed a method called Testing Theory-based Quantitative Predictions, successfully applied to predicting outcomes and effect sizes in smoking cessation, diet behavior, and sun protection, with the potential for wider applications. With $\$ 60,000,000$ in external funding, Velicer also helped engage a large cadre of students and other colleagues to study methodological models for a myriad of health behaviors in a widely applied Transtheoretical Model of Change. Unwittingly, he has engendered indelible memories and gratitude to all who crossed his path. Although Wayne Velicer left this world on October 15, 2017 after battling an aggressive cancer, he is still very present among us. 


\section{A Tribute to the Mind, Methodology and Mentoring of Wayne Velicer}

How do you measure a life, quantify where it's been and what it left behind? We don't imagine that this is a small task, especially for a complex and multifaceted individual like Wayne Velicer. Even a quick perusal of his accomplishments is awe inspiring. Velicer defined the very essence of his field and it would be hard to find another who contributed as much or as clearly as he did in combining and elevating behavioral health and quantitative science. His research, grants, teaching, and presentations resonated with crystal clarity, increasing our understanding reaching far and wide around the globe. If Wayne Velicer could be characterized by his main components and contributions, and we are not sure that this could easily be accomplished, he would be noted for advancing and informing the following arenas that include quantitative methodology, behavioral health, and making time for people.

\section{Quantitative Methodology}

Velicer had a curious and engaging mind, liking nothing more than to delve into the methodological essence of ideas and constructs. Moreover, he took the time to include others in his productive research, setting the groundwork for notable contributions in component analysis, longitudinal analysis, and cluster analysis.

\section{Principal Components Analysis}

A core interest, and perhaps his most salient methodological focus, concerned studying the merits of forming a few concentrated combinations of information from a larger number of variables in order to understand the nature of a construct (e.g., Velicer, Eaton, \& Fava, 2000). This work chiefly focused on the practice of principal components analysis (PCA), the topic of Velicer's doctoral thesis and at least 20 published articles of his. A highly cited paper in this forum was the development of a reliable procedure for determining the number of components to 
retain from assessing the minimum average partial (MAP) correlations among items (Velicer, 1976). A decade later, Velicer's MAP and Horn's (1965) parallel analysis were found to work best in comparison to other existing methods, such as the Cattell's (1966) scree plot, Kaiser's (1960) eigenvalue greater than 1 rule, and Bartlett's (1950) chi-square test, across several conditions varying sample size, number of variables per component, number of components, and the size of the loadings (Zwick \& Velicer, 1986).

A year after his article on MAP, Velicer (1977) provided a coherent comparison showing the similarity of factor, image, and principal component patterns that previewed a special section of Multivariate Behavioral Research on this general topic 13 years later, in collaboration with Douglas Jackson and other methodologists in this area. Among a dozen articles in this landmark venture, Velicer and Jackson (1990a, 1990b) conducted a Monte Carlo study to compare the performance and main features of PCA and factor analysis under varying conditions, as well as provided a summary of some general conclusions about both types of analyses. Velicer and Jackson recognized that factor analysis focuses on common variance while taking unique or error variance into account, whereas PCA attempts to account for all variance via linear combinations of the original variables. Despite this notable distinction, Velicer and Jackson concluded, both methods often perform well, and yield comparable conclusions in similar circumstances. Later, Lew Goldberg and Velicer (2006) published an instructive description of exploratory factor analysis.

Velicer collaborated with his students on other important papers related to PCA. Edward Guadagnoli and Velicer (1988) published a high-impact article showing the relationship between sample size and component stability. They showed that whereas a large sample size and a number of variables with high loadings (e.g., at least .60) per component produced the best 
stability, if components had several high loadings for several marker variables per component, having a smaller sample size (e.g., 50 to 100) may still yield some stability. Thus, they determined that it was more important to have more variables and with high loadings than to have a specific variable to component ratio. In another paper, Guadagnoli and Velicer (1991) verified that having high loadings and larger sample sizes also helped in matching pattern matrices across different samples, with several matching indices (i.e., the coefficient of congruence, the s-statistic, and kappa: k), whereas a simple Pearson's $r$ was not as effective in matching pattern matrices regardless of the size of the loadings or sample.

In another productive student collaboration, Fava and Velicer (1992) conducted simulations to investigate the effects of extracting too many dimensions when conducting PCA or maximum likelihood (ML) factor analysis. They varied sample size (from 75 to 450), loading size (from .4 to .8), and number of variables per factor (from 4 to 12). Over-extraction did not have as much effect on the factor scores with a large sample size and large loadings. However, the combination of a small sample size and low loadings caused the most problems. A subsequent paper delineated the effects of extracting too few dimensions (Fava \& Velicer, 1996).

A couple years later, Velicer and Fava (1998) published another highly cited paper where they conducted a simulation study to investigate what conditions affected the ability to recover an accurate factor pattern. They varied sample size (from $\mathrm{N}=50$ to 800 ), the ratio of variables to factors (i.e., 3, 4 or 5 per factor), and the size of the loadings (i.e., .4, .6 or .8). Results showed that all three conditions had some effect, with the most variability, and hence the least factor pattern recovery, occurring with a sample size of 50, and loadings of .40. However, findings also revealed that a factor pattern could still be recovered even when not all conditions were optimal, such that a large sample size (e.g., 800) could compensate for low loadings (e.g., .40). 
Structural Equation Modeling. Another highly cited collaboration further extended the findings found with PCA on a different, although somewhat similar method, namely, structural equation modeling (SEM). Ding, Velicer, and Harlow (1995) conducted a simulation study to assess the effects of sample size (i.e., 50, 100, 200 or 500), loading size (i.e., .5, .7, or .9), number of variables per factor (i.e., 2, 3, 4, 5, or 6), and estimation method (ML vs. generalized least squares: GLS) on the behavior of several fit indices (i.e., chi-square/df; normed fit index: NFI, nonnormed fit index: NNFI, centrality $m$ index, relative noncentrality index, and comparative fit index). Similar to the findings that Velicer and his collaborators found with PCA, SEM behaved better with larger sample sizes (i.e., 200 or more), higher loadings (i.e., .7 or higher), and having 3 variables per factor. Specifically, results showed fewer improper solutions, less noncovergence, and less bias in the fit indices with these conditions, and having one or two of these preferred values could compensate for not having the other. Further, the NNFI appeared to show less bias than the other fit indices under the conditions listed, whereas the NFI showed the most bias. Additionally, GLS tended to show less bias than ML for the fit indices tested.

\section{Longitudinal Analysis}

In addition to understanding the nature of constructs through methods like PCA, factor analysis and SEM, Velicer delved into methodology that illuminated how individuals change over time, helping to popularize the use of time series in behavioral research. In this vein, he coauthored papers with another great methodological thinker, Rod McDonald, discussing time series without identification (Velicer \& McDonald, 1984), and the use of cross-sectional time series (Velicer, \& McDonald, 1991). In a number of fruitful collaborations with his students, Velicer assessed the accuracy of identifying the correct time series model (Velicer \& Harrop, 1983), compared several approaches to analyzing the change in a longitudinal time series before 
and after an intervention (Harrop \& Velicer, 1985), evaluated computer programs for analyzing time series (Harrop \& Velicer, 1990a, 1990b), and compared procedures for analyzing time series with missing data (Velicer, \& Colby, 2005). Velicer also co-authored a general description of time series (Velicer \& Fava, 2003), and with two other students provided a clear delineation of idiographic methods that focused on how individuals change over time, as opposed to focusing on a large group at a single time point (Velicer, Hoeppner, \& Palumbo, 2012).

In another paper with an overarching focus, Harrington and Velicer (2015) researched a range of published studies to compare visual and statistical approaches to assessing time series also known as single-case designs. Visual analysis (VA) is often used in applied behavior analysis research and involves inspection of a graph of the data over time. In contrast, interrupted time series analysis (ITSA) is a statistical method that takes into account the degree of dependency between adjacent points, provides information on the level and slope and the change in each, and allows for the calculation of an effect size. Thus, ITSA provides more precise examination of the data, although it is more complex to use than VA and tended to be used more in econometrics before it was brought to the attention of behavioral science by Glass, Willson, and Gottman (1975/2008). A further deterrent to using ITSA is that it requires having 100 or more time points of data and can still yield biased results if a model is not initially identified correctly. Velicer and McDonald (1984), along with Harrop and Velicer (1985), introduced a general transformation model that offered a simpler method than that offered by Glass et al., in that the method by Velicer and colleagues did not require model identification before estimating the time series parameters. Moreover, Harrington and Velicer showed that whereas VA of longitudinal data before and after an intervention provided some insight into the pattern of change, the statistical use of ITSA was more accurate and less biased. Further, new technology 
for converting graphs to data such as UnGraph ${ }^{\circledR}$ (Biosoft, 2004), an R program for converting between graphs and data (Bulté, \& Onghena, 2012), and another reliable open source program, WebPlotDigitizer (Rohatgi, 2015), make it easier to analyze time series data in the literature that is only shown in graphs or to convert raw time series data to graphs (see a review in: Moeyaert, Maggin, \& Verkuilen, 2016). That is, the new technology would allow researchers to extract the actual time-series raw data points from visual graphs published in the literature. Thus, data that were previously only assessed by VA could now also be analyzed with ITSA, which would allow a more precise, quantitative assessment of the data, including an effect size that could be included in meta-analysis studies. Additionally, the technology could also allow raw time series data to be depicted in a graph, providing the capability of both visual and statistical analyses of relevant longitudinal data. Velicer would have supported the growing interest in the use of single-case designs and the ease in which researchers can understand and analyze these kinds of data with open source software (see: Manolov \& Moeyaert, 2016).

In applied longitudinal research, Harrington, Velicer, and Ramsey (2014) used time series analysis and dynamic cluster analysis to delineate different patterns of alcohol use across a sample of 177 adults, assessed at 180 time points. They identified eight clusters that helped to inform how interventions could be constructed to reach these varying types of alcohol users.

Velicer also collaborated with students on a latent transition analysis (LTA) of smokers across time in five stages of change (Martin, Velicer, \& Fava, 1996) in order to see how individuals moved from not even thinking about quitting smoking, up to maintaining smoking cessation for six months or more. In another application of LTA, Velicer, Martin, and Collins (1996) compared the trajectory of behavior change for smokers in an intervention versus a 
control group to consider patterns of making changes or regressing, depending on the initial stage of change.

In a longitudinal computer-delivered and tailored intervention study, Brick, Redding, Paiva, Harlow, and Velicer (2017) followed a sample of over 4,000 adolescents from $6^{\text {th }}$ grade through $9^{\text {th }}$ grade. They found that, compared to the control group, adolescents in the intervention group were more apt to move forward toward maintaining positive behavior change with regard to increasing physical activity and the consumption of fruits and vegetables. The improvement occurred mainly from sixth to eighth grade, with not much change from eighth to ninth grade. Another study showed similar effects in a longitudinal study of smoking and alcohol use in adolescents (Brick, Redding, Paiva, \& Velicer, 2017).

\section{Cluster Analysis}

In another methodological area, Velicer made use of cluster analysis in order to shed light on the natural groupings of individuals within specific health behaviors, sometimes over time. Cluster analysis is useful when it is important to recognize that a sample of individuals is not a homogeneous group and to uncover a subset of groups that behave differently. Velicer taught a class on Parsimonious methods at the University of Rhode Island that discussed, among other topics, the method of cluster analysis for understanding a $(\mathrm{p} \times \mathrm{N})$ matrix of $\mathrm{N}$ individuals assessed on $\mathrm{p}$ clustering variables. In a productive and informative series of papers, Velicer and his colleagues and students applied cluster analysis to understand different patterns of how people change and to create effective interventions that were geared toward specific concerns or behaviors (e.g., Velicer, Redding, Anatchkova, Fava, \& Prochaska, 2007).

For example, Prochaska, Velicer, Guadagnoli, Rossi, and DiClemente (1991) studied a sample of more than 500 adults over a two-year project using the method of dynamic typology 
clustering to understand how subgroups of smokers change across time. They found that focusing on the advantages of smoking, and the temptations to smoke, decreased across stages of change, from Precontemplation when someone is not even considering change, up through Maintenance when individuals have successfully changed their behavior for six months or longer. Conversely, self-efficacy for quitting smoking increased over time and across these stages. Results helped researchers see that it would be useful to intervene on these variables to help promote behavior change. Several years later, dynamic typology clustering was again used to further understand different subsets of behavior change in a sample of over 2,000 smokers, over a two-year period (Norman, Velicer, Fava, \& Prochaska, 1998). The methodology allowed Velicer and his colleagues to identify several clusters of individuals with differing patterns of change, with one group staying the same, a second group moving forward with positive change, a third group moving back and forth through stages of change, and a fourth group that regressed backward after initially making positive change. The findings were further replicated on a representative sample of over 4,000 adult smokers, offering more validation and generalization for the clusters of behavior changers (Norman, Velicer, Fava \& Prochaska, 2000). Focusing on a different behavior, Norman and Velicer (2003) also showed how different clusters of exercisers could be identified in a sample of 346 adults. Their results offered insight into different patterns regarding seeing the advantages, disadvantages and self-efficacy for exercising, which helped inform effective interventions depending on the patterns that emerged in the set of clusters.

\section{Testing Theory-based Quantitative Predictions}

Velicer was also a proponent of using effect sizes and confidence intervals instead of relying on a dichotomous decision rule with null hypothesis significance testing (NHST). To those who knew him, it was more than plain that he could easily do without NHST, which he 
found limiting and misleading. To this end, Velicer and his colleagues developed a method called Testing Theory-based Quantitative Predictions (TTQP) to use previous theory and empirical studies to make predictions about effect sizes. In an initial testing of TTQP, Velicer, Norman, Fava, and Prochaska (1999) found support for 36 of 40 predictions regarding smoking cessation outcomes based on the transtheoretical model. Velicer, Cumming, Fava, Rossi, Prochaska, and Johnson (2008) conducted another TTQP study that successfully predicted 11 of 15 effect size predictions of smoking behavior in a sample of almost 4000 smokers. In another article, Velicer, Brick, Fava and Prochaska (2013) used TTQP to make 40 predictions on the expected effect sizes for how much smokers would move through the stages of change over a 12month period. Results were correct for 32 of the 40 predictions (i.e., $80 \%$ correct), providing more precision, theoretical support and magnitude of the effects than would be obtained from conventional NHST. A follow-up article used the TTQP to try and extend the method from previous smoking findings and theory to predictions beyond just smoking (Brick, Velicer, Redding, Rossi, \& Prochaska, 2016). This study found that whereas predictions based on previous studies and expert panel input from smoking research slightly improved to $86.6 \%$ (i.e., 13 of 15 predictions were supported), only $43.3 \%$ of the predictions (i.e., 13 of 30 ) successfully predicted diet behavior, and just $26.6 \%$ (i.e., 8 of 30) of the predictions were successful with sun protection. Results from this 2016 assessment highlighted that TTQP works best when there is specific research and theory that has already been conducted on a behavior (e.g., smoking), while still encouraging researchers to build on previous research and theory to make quantitative predictions on effect sizes to further strengthen the knowledge base in those and other areas.

\section{Behavioral Health}


A prolific researcher, Velicer was a creative and innovative collaborator in the area of behavioral health who was not afraid of exploring new ideas and working with people who had different strengths that could be combined to produce a broader understanding than could be had with a single perspective. James Prochaska was undoubtedly Velicer's most frequent and prolific collaborator, co-authoring well over 100 articles, and together with Carlo DiClemente and others developed and extended what was called the transtheoretical model (TTM) of change. With extensive external funding from the National Cancer Institute, the National Institutes of Health and other agencies, they galvanized numerous students and other colleagues to discern how to move people through the stages of change (DiClemente, Prochaska, Fairhurst, Velicer, Velasquez, \& Rossi, 1991), from precontemplation when not even thinking about behavior change, through to consideration or contemplation of a change, to preparation for making a change, and then getting into action and finally to maintenance of a change for six months or longer. Velicer and his colleagues realized that people work through a decisional balance to weigh the pros and cons of making a behavior change (Velicer, DiClemente, Prochaska, \& Brandenberg, 1985), where the cons seem to predominate until individuals make efforts to change, and then the pros or advantages start to come to the forefront, moving them forward into action. Self-efficacy and confidence were also identified as motivators to moving forward and preventing relapse (Velicer, DiClemente, Rossi, \& Prochaska, 1990), aided by various behavioral and experiential processes of change such as helping relationships and consciousness raising, respectively (Prochaska, Velicer, DiClemente, \& Fava, 1988). Velicer and his colleagues also championed the development and use of individualized expert computer systems to help understand and intervene to evince change in multiple health behaviors (e.g., Velicer, Prochaska, Bellis, DiClemente, Rossi, Fava, \& Steiger, 1993; Prochaska, Velicer, Redding, Rossi, J. S., 
Goldstein, DePue, Greene, Rossi, S. R., Sun, Fava, Laforge, Rakowski, \& Plummer, 2005). This work led to the development of individually-tailored, technology-based interventions, which dominate the field of health behavior change today.

The prodigious research of Velicer and his colleagues had a large impact on the field, helping to delineate their TTM model to inform how individuals make health behavior changes, with one of their articles earning more than 7300 citations (Prochaska \& Velicer, 1997), and another article demonstrating the application of the TTM in 12 different behaviors having over 3000 citations (Prochaska, Velicer, Rossi, J., Goldstein, Marcus, Rakowski, Fiore, Harlow, Redding, Rosenbloom, \& Rossi, S. 1994). Another highly cited article (i.e., over 3100 citations) highlighted the need to focus on multiple stages of change for smoking cessation, as opposed to simply studying smokers versus nonsmokers (DiClemente, Prochaska, Fairhurst, Velicer, Velasquez, \& Rossi, 1991). A sampling of the literature documents the merit and reach of the TTM in illuminating the stages and mechanisms of behavior change across a plethora of areas, focusing initially on psychotherapy (McConnaughy, Prochaska, \& Velicer, 1983) and smoking cessation (Velicer, Prochaska, Rossi, \& Snow, 1992), and extending to alcohol use prevention in adolescents (Babbin, Harrington, Burditt, Redding, Paiva, Meier, Oatley, McGee, \& Velicer, 2011), condom use (Harlow, Prochaska, Redding, Rossi, Velicer, Snow, Schnell, Galavotti, O'Reilly, \& Rhodes, 1999), dietary behavior (Greene, Rossi, S. R., Rossi, J. S., Velicer, Fava, \& Prochaska, 1999), HIV prevention (Prochaska, Redding, Harlow, Rossi, \& Velicer, 1994), mammography (Rakowski, Dubé, Marcus, Prochaska, Velicer, \& Abrams, 1992), physical exercise (Reed, Velicer, \& Prochaska, 1997), stress management (Velicer, Prochaska, Fava, Norman, \& Redding, 1998), substance abuse prevention (Velicer, Redding, Paiva, Mauriello, Blissmer, Oatley, Meier, Babbin, McGee, Prochaska, Burditt, \& Fernandez, 2013), sun 
protection (Prochaska, Velicer, Rossi, J. S., Redding, Greene, Rossi, S. R., Sun, Fava, Laforge, \& Plummer, 2004), and other behaviors such as seatbelt use, avoiding high fat food, eating highfiber foods, weight reduction, and conducting cancer self-exams in a sample of older adults (Nigg, Burbank, Padula, Dufresne, Rossi, Velicer, Laforge, \& Prochaska, 1999).

\title{
Making Time for People
}

Amidst his talents for quantifying and measuring, it was also clear that people counted in Wayne's world. He liked nothing more than spending time with others, and talking about ideas and life's happenings over a sumptuous meal accompanied with some exquisite wine. The first author's husband, Gary, aptly shared that "Wayne cared deeply and listened intently, always quick to ask what was going on in others' lives and to see how they were doing."

Numerous people, a subset of whom provide input below, have spoken about how much they appreciated him as a colleague, teacher, mentor, and friend. They share brief vignettes of their time with Wayne, each trying to capture even a portion of the larger whole that was Wayne Velicer and the lasting mark he had and will continue to have on quantitative and health psychology. Each vignette contributor is listed alphabetically by name, with their current position and affiliation, as well as their relationship to Wayne, noting that many had multiple roles, such as being a colleague in the Society of Multivariate Experimental Psychology (SMEP), for which Wayne was President in 2008-2009, or during Quantitative Training for Underrepresented Groups (QTUG), for which Wayne helped write the National Science Foundation grant that funded 5 years of QTUG conferences. Further, at least half of these individuals considered Wayne a mentor, and at least half were research collaborators.

\author{
Leona Aiken: President's Professor, Emerita, Founding Chair, Quantitative Psychology \\ Program, Arizona State University; Former college classmate, and SMEP colleague
}


Wayne and I were graduate school classmates at Purdue University, where my overall impression of him was "scary smart." There was one shared influence of the Purdue University environment that I discovered only long after we had graduated. We approached playing bridge very similarly, with the identical bidding conventions, though we had never played bridge together before. At the 1994 SMEP meeting in Princeton, NJ, we played as bridge partners for the first and only time. Wayne was a delightful bridge partner with impeccable grace at the table; in a match against excellent SMEP bridge players, we emerged the victors.

Steve West and I had the good fortune to share many meals with Wayne both stateside and abroad. Wayne and I always planned dinners for the first evening of SMEP with spouses and colleagues. Wayne knew a lot about food and wine-yet he espoused some views with which I disagreed - for example, that he found nothing to like in the white burgundies.

Wayne went through hard times all at once- - personal loss and illness-- with great courage. During these times, it was always a gift to me to spend time with Wayne. He prevailed in his work and kept his future orientation. Wayne remarried on 11-11-11. Seeing my treasured friend Wayne so happy and spending time with Wayne and his wife Anna are among my cherished memories.

\section{A. Nayena Blankson: Professor of Psychology, Spelman College, Atlanta, GA; QTUG and SMEP colleague}

Throughout my academic career, I have been blessed to have several amazing mentors, whom I call academic cheerleaders. These individuals are the ones who you know are always in your corner; they're always there if you need advice, but most of all, they cheer you on and provide encouragement as you pursue your academic goals. Having these cheerleaders may be all the motivation one needs to aim higher and higher. Wayne Velicer was one of these 
individuals in my life. I met Wayne in 2005 when I attended my first SMEP meeting as a guest of my graduate school mentor (and another cheerleader), John L. Horn. Over the years, I had the pleasure of interacting with Wayne at other SMEP meetings as well as at the Quantitative Training for Underrepresented Groups conferences. He was always supportive, including of my efforts to obtain grant funding to train students in statistics. He was eager to not only serve as a member of the advisory board, but to serve as a mentor to students. I am grateful to have had the chance to meet Wayne and to have been mentored by him.

\section{Gwyneth M. Boodoo: Founder and President, GMB Enterprises, New Jersey; SMEP and QTUG colleague}

It was a joy to know Wayne as a fellow SMEP member. He was a gentleman, always thoughtful and kind even when being brutally honest with you. He may be the only person I know who still wore suspenders, at least that I could see, as he walked in his unique way around the SMEP conference room. I remember how kind he and his late wife Sue were to my sister who accompanied me to the Colorado SMEP meeting. And I remember how happy he was when introducing his new wife Anna and later regaling me with stories of their renovation of a retirement home in Florida which, sadly, he did not get enough chance to enjoy much as far as I know. As a new SMEP member many years ago who stood out in many ways, I truly appreciated the many members who went out of their way to welcome me. And Wayne was one of this group. I will always treasure his friendship and will miss talking with him and just knowing he is around. Like many others who are now gone, Wayne contributed positively to the continued growth of the SMEP organization. Thanks, Wayne, for all you did. 


\section{Leslie Ann D. Brick: Assistant Professor, Associate Director, Quantitative Science Program, Alpert Medical School of Brown University, RI; former doctoral student and research collaborator}

In 2010 I had applied to several graduate programs and was thrilled to receive an interview with Wayne Velicer at the University of Rhode Island. I was nervous, but felt prepared for all the tough questions that one may anticipate in an interview for graduate school. We talked a little about statistics, a little about research, but mostly about cheese curds (we both have familial ties to rural Wisconsin). Five not-so-short years later, I had a $\mathrm{PhD}$ and several opinions on principal components and factor analysis.

During my time at URI, among many things, Wayne introduced me to lobster, drilled into my mind the importance of idiographic research, allowed me the freedom to follow my whims (read: extra classes and side jobs), and twice supported my attendance to the student preconference of SMEP. He modeled the importance of taking time to enjoy family and life - an important lesson for all students. He also had a rare ability to vehemently disagree with people while also holding them in great respect - another important lesson. These experiences, along with his excellent mentorship (and his matrix-algebra heavy courses), were monumental to my training and success in quantitative methods and psychology as a whole. Wayne challenged me, kept me on track, and gave me the independence I needed to succeed. I am grateful for the time, patience, and humor that he shared with me as a graduate student and as an early career scientist. I miss him greatly and think about him often. His passing is truly a loss to his family, friends, students, and collaborators. May he live on in our work and in our memories. 


\section{Linda M. Collins: Distinguished Professor and Director, The Methodology Center and Department of Human Development \& Family Studies, the Pennsylvania State University, State College, PA; SMEP colleague and research collaborator}

I first met Wayne more than 30 years ago, when I applied for a position in his department at the University of Rhode Island. Wayne and his late wife, Sue, used to love to have visitors to URI stay at their home. I was their guest on that visit, and had a great time. Although I was not offered the position, Wayne and I became friends. This was characteristic of Wayne; he could become friends with people under almost any circumstances. After this visit he took an interest in my career, and was a wonderful mentor.

I'm still a little embarrassed that on that visit I brought a couple of bottles of wine as a gift, not knowing I was bringing coals to Newcastle. Wayne's knowledge of wine was encyclopedic, and his wine cellar was legendary. When you dined out with Wayne, you let him order the wine. I am in awe of how he would specify not just the winery and type of wine he wanted, but also the vintage year. As far as I could tell, he kept all of this information in his head. The wines he selected were not merely enjoyable, they were sometimes a revelation.

Wayne's friendship meant a lot to me. He could be a little rough around the edges, but along with that came tremendous honesty, realism, and clarity. It wasn't until we lost him that I realized how implicitly I trusted him, and how influential his counsel has been in my life.

\section{Geoff Cumming: Professor Emeritus, La Trobe University, Melbourne, Australia; QTUG colleague and research collaborator}

Way back, Wayne invited me to visit his lab. I gave a talk about the iniquities of NHST and $p$ values, and the benefits of confidence intervals. At once it was clear that we shared many views. Wayne enthusiastically brainstormed about what estimation could do in his research. On 
the spot, he invited me to help develop a paper using confidence intervals to evaluate one of his multi-variable quantitative models. Over several years we exchanged drafts; it was exciting for me to work with such a creative, energetic, and distinguished colleague. The paper appeared in Applied Psychology: An International Review, and has provoked much comment.

My first experience of Wayne as food and wine buff, and wonderfully generous host, occurred when my wife and I visited R.I. while driving an old RV around the U.S. Thereafter, memorable meals — at venues selected by Wayne the expert—became, for me, highlights of American Psychological Association Conventions.

Wayne often mentioned that he loved visiting Australia, where he had close research colleagues, although we managed to meet up here only once. Besides his enduring friendship and expansive hospitality, I remember most warmly his ability to ruffle scientific feathers to such creative and positive effect.

\section{Joseph Fava: Research Associate, Centers for Behavioral and Preventive Medicine, The Miriam Hospital; former doctoral student and research collaborator}

In 1983, in my mid-30's, I initiated a career change and began to study Psychology. I had the good fortune to take a statistics class taught by Wayne, who encouraged me to apply to the graduate Psychology program at URI to study Quantitative Psychology as his student. As a mentor, Wayne was a constant source of unique ideas and projects. Initially I shared a small office with tens of thousands of IBM punch cards, written in FORTRAN, that had traveled East with Wayne. Learning FORTRAN in my 'spare' time, overworking the computer center card reader, nudging the FORTRAN programs and their countless subroutines to perform, while submitting thousands of programs via ancient job control language at all hours of the day and night, we conducted several 'early-era' Monte Carlo studies. This work, resulted in five co- 
authored peer-reviewed publications and included my Master's and Doctoral degree research, as we investigated key issues in principal components and factor analysis. I continued to work directly as a colleague with Wayne for 15 years on various NIH funded research projects. My daily contact with Wayne ended when I left URI in 2004, but during our active collaborations, we were co-authors on more than 30 peer-reviewed papers, 100 scholarly presentations, and several book chapters. Beyond the scholarly work and mentorship, Wayne was a great friend, a 'gourmet-scholar' who introduced me to the arts of wine collecting and fine dining, engaged in witty conversation, and had truly unique insights on work and life.

\section{Matthew S. Goodwin: Interdisciplinary Associate Professor, Dept. of Health Sciences and the College of Computer and Information Sciences, Northeastern University, Boston, MA; former doctoral student and research collaborator}

It is with honor and a heavy heart that I memorialize Wayne Velicer, my longtime mentor, colleague, and friend. Wayne was my major professor and doctoral advisor at the University of Rhode Island from 2003-2008. His positive influences on me are countless and continue to this day. He was a master teacher, able to explain complicated concepts in an approachable and engaging way. He was committed, spending countless hours offering students and colleagues guidance, encouragement, and support. He was courageous, willing to challenge the status quo for the advancement of public health and methodological science. He was critical, rightfully reminding us that statistical averages do not always capture the complexity of individual people and behavior. He was optimistic and passionate, guided by the belief that people could change their own behavior through lifestyle modifications if the appropriate conditions were facilitated. He was intellectual and facile, able to read and synthesize otherwise disparate fields of psychology, statistics, engineering, and econometrics. He was vanguard, 
simultaneously championing population and single-case designs and longitudinal methods to enhance data collection, analysis, and inference. And perhaps most memorable of all, he was a connoisseur and avid devotee of quality travel, food, and wine, making him a great pleasure to spend time with. You will be missed greatly Wayne, and I feel fortunate to be one of the many recipients of your numerous talents and influence.

\section{Bettina B. Hoeppner: Associate Professor of Psychology, Massachusetts General Hospital, Harvard Medical School, Boston, MA; former doctoral student and research collaborator}

When I started my graduate training, my goal was to study spirituality and its impact on the quality of life. All that changed when I met Wayne. Ok, not quite, but he most assuredly and substantially changed the course of my career, starting with the moment I walked into his class during my first week of classes. The course was about the transtheoretical model of behavior change and its myriad applications. The two key thoughts I took with me, however, were that technology could be leveraged to support health behavior change, and that change is a process. As so many things in life, in retrospect, these thoughts seem quite obvious. But it was the passion and clarity with which Wayne presented these ideas that made me pause and think: if we could reach hundreds, nay, thousands of people via tailored technology-delivered messages, what would we want to say? What evidence would we need to give the right information to the right person at the right time? These thoughts have guided my training and research since then. To me, Wayne was an illuminating teacher (yes, I say that even though he made us do matrix algebra!), inspiring role-model, and supportive mentor. I will forever use his minimum average partial (MAP) procedure (Velicer, 1976), and I will be sure to take the time to enjoy life as I live it, as he modeled. 


\section{David P. MacKinnon: Foundation Professor of Psychology, Arizona State University; SMEP colleague}

I was a fan of Wayne Velicer before I met him. He represented the ideal of a scientist committed to the development and application of methods to answer important applied research questions in health. My favorite papers described his technical work on suppression, methods to assess dimensionality, and missing data. I also liked his contributions to behavior change theory, including his work on the influential transtheoretical model. Wayne was a genius at marshalling modern statistical methods to help answer gripping substantive questions. After I met Wayne, I was even more of a fan. He was joyously entrenched in the investigation of both important applied health questions and advanced statistics. I enjoyed Wayne's company at SMEP each year and will miss that very much. I had the pleasure of staying with Wayne at his house when I gave a workshop at URI. In all my time with Wayne, I enjoyed the spirit of such a decent, thoughtful, funny, and clever polymath. I wish I could share a glass of wine with him now.

\section{Peter C. M. Molenaar: Distinguished Professor of Human Development and Family} Studies, The Pennsylvania State University; SMEP colleague and research collaborator I visited Wayne Velicer for the first time at his impressive Cancer Prevention Research Center at the University of Rhode Island in June 2008. Wayne had contacted me because of our shared interest in time series analysis. I stayed in his house and we had intensive discussions about psychometrics. I presented a talk at his Center on the consequences of ergodic theory, pertaining to the relation between results obtained in analogous analyses of inter-individual and intra-individual variation. Wayne was very interested in the topic of my talk and invited me to carry out some shared work. We had additional visits with Wayne in the company of my wife Madeleine and our youngest daughter Fran. Wayne was a very entertaining host; it was a real 
treat to be in his company. Wayne quickly grasped the implications of ergodic theory for quantitative psychology and presented his views in his 2009 presidential address to the Society of Multivariate Experimental Psychology entitled: Ideographic research: Understanding individual change over time. In this address he presented four examples drawn from research published by his group in which there was no relation between results obtained at the level of individual subjects and the population level. Those were strong examples of the effects of nonergodicity which I since use in my graduate course on this topic. I fondly remember the dinners which Wayne organized at each annual SMEP meeting, usually in the company of Leona Aiken, Steve West and Will Shadish. Wayne is missed very much.

\section{Joseph Rodgers: Lois Autrey Betts Professor of Psychology and Human Development, Peabody College Vanderbilt University; SMEP colleague}

Wayne Velicer was at the same time charming and contentious, agreeable and argumentative, insightful and infuriating. I first became friendly with Wayne when I was elected to the Society of Multivariate Experimental Psychology, and had the pleasure of a front row seat, watching Wayne and other titans of Quantitative Psychology argue over the legitimacy of Principal Components Analysis. (Believe me, it does matter a great deal to people in our field!) I became closer friends with Wayne when he publicly and resoundingly rejected my social contagion model of cigarette smoking among adolescents. When I called him on it in private an hour or so later, we talked for a while, found common ground, and each learned something from the other. I became close friends with Wayne when he invited me to the University of Rhode Island to give a talk. In front of my eyes, this hard-driven, opinionated, and frustrating psychometrician became the world's most charming host. We ate (and then ate some more). We told stories about our many common friends. We shared jokes, and then we ate even more. He 
introduced my talk as though we'd been building a deep relationship for many years -- only because we had been. He was an excellent scholar, and worked on real and important issues. He was an excellent friend. I speak for many, to simply express that we already miss Wayne.

Joseph S. Rossi: Professor, Department of Psychology, University of Rhode Island, former doctoral student, research collaborator, and SMEP colleague

I met Wayne in the spring of 1975: he was 31, I, 24. He was a beginning assistant professor, interviewing me for the $\mathrm{PhD}$ experimental psychology program at URI. Once satisfied with my GRE-Quant score, we talked science-fiction for the rest of the interview. We both liked Asimov (whom he knew) and Clarke; we disagreed on Lem. Wayne was like that - at any moment, he could discuss almost any topic, perhaps the only true polymath I've ever met. We discussed wine endlessly. I cannot drink a wine now without imagining what Wayne would think of it, and how much I would like to share it with him. I miss him a great deal and still think of him often. Just last night I had a dream. I had come from a meeting and needed Wayne's advice. His office door was open and lit from within, but I could not see him or hear him. I lingered for a few minutes, a bit confused, not knowing what to do. Slowly I walked away, and looking back as I left, saw that the light emerging from his office still illuminated the darkened corridor behind me. Wayne is gone but his light remains with me and helps illuminate the way ahead. It has been said of others, but can be said of Wayne as well, that some voices are so vibrant and vivid that it is difficult to think of them as stilled.

Allie Scott: Research Scientist, New York State Department of Health, New York City, NY; Wayne's last doctoral student before Wayne died

Just a few months after I finished my $\mathrm{PhD}$, Wayne passed away. Wayne's passing was very difficult for my family because he did so much for me. I was Wayne's last student and 
though our time together was unexpectedly brief, we managed to have a wonderful, productive relationship, and I am glad that I had the opportunity to work with and get to know him. When I first met Wayne, I remember my first impression of him as a kind, expressive, and goodhumored person. In addition, the way he carried himself made it seem like he was a cool cross between professor Indiana Jones and Santa Claus. I admired him for his many impressive achievements and quickly grew to love Wayne as a person. We often talked about our common interests, including our love for travel, wine and good food. But above all else, he especially enjoyed spending as much of his free time as he could with his family. My heart goes out to all his children, grandchildren, and lovely wife Anna. I would not be where I am today if it were not for Wayne's strong leadership and support. He will be missed.

\section{James H. Steiger: Professor Emeritus, Vanderbilt University, Nashville, TN; SMEP colleague and research collaborator}

About 30 years ago, Wayne invited me to come to Rhode Island. I stayed at his home and got to know Wayne, his wife Sue, and their sons Scott and Clayton. Wayne's research team and I began collaborating on an automated Expert System for Smoking Cessation. The initial work was intense. Some computer programming was behind schedule, the chief programmer had quit, and we were basically starting from scratch and facing a deadline. I was amazed at the spirit, cohesiveness, and ability of Wayne's research team.

But it wasn't all work. The Velicers were wonderful hosts. I got a quick course in gourmet food and fine wine, especially Australian Shiraz, my favorite ever since. His sons took turns trouncing me at computer games (except when they deliberately let me win), then Wayne invited me to his "relaxed" weekly full court basketball game, where I discovered that Wayne played even harder than he worked. 
Wayne's unique combination of dynamic energy, pragmatic intelligence, organizational skills, and dedication are qualities I could admire but never match. There was love, warmth, and joy in his home. In the game of life, he touched all the bases.

\section{Stephen G. West: Professor, Arizona State University, Gastprofessor, Arbeitsbereich Methoden und Evaluation, Freie Universitaet Berlin; SMEP colleague.}

Wayne did his MA thesis with Ben Winer and his $\mathrm{PhD}$ dissertation with Peter

Schönemann at Purdue University. Wayne recounted a story of the challenge of completing his MA thesis where although Winer was satisfied with his work, he wanted a different notational system. In the era before PCs, too many mistakes meant retyping yourself or hiring a professional typist for the then princely sum of $\$ 1-\$ 2$ per page. Wayne retyped his thesis with the new notation, although Winer was still not happy and suggested still another notational system. Wayne retyped his thesis again, yet Winer was still not satisfied and suggested yet another notational system — one identical with Wayne's original. Wayne raced home, found his original thesis, and raced back to Winer's office and got this final (original) thesis approved by Winer.

Wayne's career straddled quantitative psychology and public health. He published outstanding basic quantitative work and applied sophisticated methods to important public health problems. Beyond his high impact published work, Wayne held wonderful conversations and presentations about then little-considered issues such as differences between the approaches of quantitative psychologists and biostatisticians, the value of an idiographic perspective with time series data, and the importance of considering alternative data generation models in simulations. Wayne's friends and colleagues will miss his many cogent insights about methods, psychology, public health, and life over fine food and wine at the many dinners he helped organize. 


\section{Conclusion}

So far did he travel, so much he did see

He had vision and insight, engaging was he

Though certainly true, he could challenge and more

Holding fast to his viewpoints while he had the floor

He still had much grace, treating friends with such care

Over good talk and wine and some sumptuous fare

His mind was on methods, components a few

To make sense of data, and clarify, too

Behavioral health, interventions, as well

Conveying effects in a story to tell

That was clear and was cogent and made sense to all

His talent for research was sure to enthrall

Though we find ourselves wishing we had him here still

His friendship, his wisdom, did give us our fill

Now we move on without him, this enchanting mind

Leaving us with such memories, both winsome and kind 


\section{References}

Babbin, S. F., Harrington, M., Burditt, C., Redding, C. A., Paiva, A., Meier, K., Oatley, K., McGee, H., Velicer, W. F. (2011). Prevention of alcohol use in middle school students: psychometric assessment of the decisional balance inventory. Addictive Behaviors, 36, 543-546. doi: 10.1016/j.addbeh.2011.01.010

Bartlett, M. S. (1950). Tests of significance in factor analysis. British Journal of Psychology, 3, 77-85. doi.org/10.1111/j.2044-8317.1950.tb00285.x

Biosoft (2004). UnGraph ${ }^{\circledR}$ for Windows (Version 5.0). Cambridge, UK: Author.

Brick, L. A., Redding, C. A., Paiva, A. L., Harlow, L. L., \& Velicer, W. F. (2017). Intervention effects on stage of change membership and transitions among adolescent energy balance behaviors. Multivariate Behavioral Research, 52(4), 485-498. doi:

$10.1080 / 00273171.2017 .1309518$

Brick, L. A., Redding, C. A., Paiva, A. L., \& Velicer, W. F. (2017). Intervention effects on stage transitions for adolescent smoking and alcohol use acquisition. Psychology of Addictive Behaviors, 31(5), 614-624. doi: 10.1037/adb0000302

Brick, L. A. D., Velicer, W. F., Redding, C. A., Rossi, J. S., \& Prochaska, J. O. (2016). Extending theory-based quantitative predictions to new health behaviors. International Journal of Behavioral Medicine, 23, 123-134. doi: 10.1007/s12529-015-9506-y

Bulté, I., \& Onghena, P. (2012). When the truth hits you between the eyes: A software tool for the visual analysis of single-case experimental data. Methodology, 8, 104-114. doi.org/10.1027/1614-2241/a000042

Cattell, R. B. (1966). The scree test for the number of factors. Multivariate Behavioral Research, 1, 245-276. doi: 10.1207/s15327906mbr0102_10. 
DiClemente, C. C., Prochaska, J. O., Fairhurst, S.K., Velicer, W. F., Velasquez, M.M., \& Rossi, J. S. (1991). The process of smoking cessation: An analysis of precontemplation, contemplation, and preparation stages of change. Journal of Consulting and Clinical Psychology, 59, 295-304. doi.org/10.1037/0022-006X.59.2.295

Ding, L., Velicer, W. F., \& Harlow, L. L. (1995). Effects of estimation methods, number indicators per factor, and improper solutions on structural equation modeling fit indices. Structural Equation Modeling: A Multidisciplinary Journal, 2, 119-144. doi.org/10.1080/10705519509540000

Fava, J. L., \& Velicer, W. F. (1992). The effects of overextraction on factor and component analysis. Multivariate Behavioral Research, 27, 387-415. doi: $10.1207 / \mathrm{s} 15327906 \mathrm{mbr} 2703 \_5$

Fava, J. L., \& Velicer, W. F. (1996) The effects of underextraction in factor and component analysis. Educational and Psychological Measurement, 56, 907-929. doi.org/10.1177/0013164496056006001

Glass, G. V., Willson, V. L., \& Gottman, J. M. (1975/2008). Design and analysis of time-series experiments. Boulder, CO: Colorado, Associate University Press.

Goldberg, L. R., \& Velicer, W. F. (2006). Principles of exploratory factor analysis. In S. Strack (Ed.), Differentiating normal and abnormal personality (2 ${ }^{\text {nd }}$ ed.) (pp. 209-237). New York, NY: Springer.

Greene, G. W., Rossi, S. R., Rossi, J. S., Velicer, W. F., Fava, J. L., \& Prochaska, J. O. (1999). Dietary applications of the stages of change model. Journal of the American Dietetic Association, 99, 673-678. doi.org/10.1016/S0002-8223(99)00164-9 
Guadagnoli, E., \& Velicer, W. F. (1988). Relation of sample size to the stability of component patterns. Psychological Bulletin, 103, 265-275. doi.org/10.1037/0033-2909.103.2.265

Guadagnoli, E., Velicer, W. F. (1991). A comparison of pattern matching indices. Multivariate Behavioral Research, 26, 323-343. doi.org/10.1207/s15327906mbr2602_7

Harlow, L.L., Prochaska, J. O., Redding, C.A., Rossi, J. S. Velicer, W.F., Snow, M. G., Schnell, D., Galavotti, C., O'Reilly, K., \& Rhodes, F. (1999). Stages of condom use in a high HIV-risk sample. Psychology \& Health, 14, 143-157. doi: 10.1080/08870449908407320

Harrington, M. \& Velicer, W. F. (2015). Comparing visual and statistical analysis in single-case studies using published studies. Multivariate Behavioral Research, 60, 152-183. doi: 10.1080/00273171.2014.973989.

Harrington, M., Velicer, W. F., \& Ramsey, S. (2014). Typology of alcohol users based on longitudinal patterns of drinking. Addictive Behaviors, 39, 607-621. doi.org/10.1016/j.addbeh.2013.11.013

Harrop, J. W., \& Velicer, W. F. (1985). A comparison of three alternative methods of time series model identification. Multivariate Behavioral Research, 20, 27-44.

Harrop, J. W., \& Velicer, W. F. (1990a). Computer programs for interrupted time series analysis: I. A qualitative evaluation. Multivariate Behavioral Research, 25, 219-231. doi: $10.1207 / \mathrm{s} 15327906 \mathrm{mbr} 2502 \_12$

Harrop, J. W., \& Velicer, W. F. (1990b). Computer programs for interrupted time series analysis: II. A qualitative evaluation. Multivariate Behavioral Research, 25, 233-249. doi: $10.1207 / \mathrm{s} 15327906 \mathrm{mbr} 2502 \_13$

Horn, J. L. (1965). A rationale and test for the number of factors in factor analysis. Psychometrika, 30, 179-185. doi.org/10.1007/BF02289447 
Kaiser, H. F. (1960). The application of electronic computers to factor analysis. Educational and Psychological Measurement, 20, 141-151. doi.org/10.1177/001316446002000116

Manolov, R., \& Moeyaert, M. (2016). How can single-case data be analyzed? Software resources, tutorial, and reflections on analysis. Behavior Modification, 41,179-228. doi: $10.1177 / 0145445516664307$

Martin, R. A., Velicer, W. F., \& Fava, J. L. (1996). Latent transition analysis applied to the stages of change for smoking cessation. Addictive Behaviors, 21, 67-80. doi.org/10.1016/0306-4603(95)00037-2

McConnaughy, E. A., Prochaska, J. O., \& Velicer, W. F. (1983). Stages of change in psychotherapy: Measurement and sample profiles. Psychotherapy: Theory, Research \& Practice, 20(3), 368-375. doi.org/10.1037/h0090198

Moeyaert, M., Maggin, D., \& Verkuilen, J. (2016). Reliability, validity, and usability of data extraction programs for single-case research designs. Behavior Modification, 40, 874900. doi.org/10.1177/0145445516645763

Nigg, C. R., Burbank, P. M., Padula, C., Dufresne, R., Rossi, J. S., Velicer, W. F., Laforge, R. G., \& Prochaska, J. O. (1999). Stages of change across ten health risk behaviors for older adults. Gerontologist, 39, 473-482. doi: 10.1093/geront/39.4.473

Norman, G. J., \& Velicer, W. F. (2003). Developing an empirical typology for regular exercise. Preventive Medicine, 37, 635-645. doi: 10.1016/j.ypmed.2003.09.011

Norman, G. J., Velicer, W. F., Fava, J. L., \& Prochaska, J. O. (1998). Dynamic typology clustering within the stages of change for smoking cessation. Addictive Behaviors, 23, 139-153. doi.org/10.1016/S0306-4603(97)00039-7 
Norman, G. J., Velicer, W. F., Fava, J. L., \& Prochaska, J. O. (2000). Cluster subtypes within stage of change in a representative sample of smokers. Addictive Behaviors, 25(2), 183204. doi.org/10.1016/S0306-4603(99)00054-4

Prochaska, J. O., Redding, C. A., Harlow, L. L., Rossi, J. S., \& Velicer, W. F. (1994). The transtheoretical model of change and HIV prevention: A review. Health Education, 21, 471-486. doi.org/10.1177/109019819402100410

Prochaska, J. O., \& Velicer, W. F. (1997). The Transtheoretical Model of health behavior change. (Invited paper). American Journal of Health Promotion, 12, 38-48. doi: $10.4278 / 0890-1171-12.1 .38$

Prochaska, J. O., Velicer, W. F., DiClemente, C. C., \& Fava, J. L. (1988). Measuring the processes of change: Applications to the cessation of smoking. Journal of Consulting and Clinical Psychology, 56, 520-528. doi.org/10.1037/0022-006X.56.4.520

Prochaska, J. O., Velicer, W. F., Guadagnoli, E., Rossi, J. S., \& DiClemente, C. C. (1991). Patterns of change: Dynamic typology applied to smoking cessation. Multivariate Behavioral Research, 26(1), 83-107.doi.org/10.1207/s15327906mbr2601_5

Prochaska, J. O., Velicer, W. F., Redding, C. A., Rossi, J. S., Goldstein, M., DePue, J., Greene, G. W., Rossi, S. R., Sun, X., Fava, J. L., Laforge, R., Rakowski, W., \& Plummer, B. A. (2005). Stage-based expert systems to guide a population of primary care patients to quit smoking, eat healthier, prevent skin cancer and receive regular mammograms. Preventive Medicine, 41, 406-416. doi.org/10.1016/j.ypmed.2004.09.050

Prochaska, J. O., Velicer, W. F., Rossi, J. S., Goldstein, M. G., Marcus, B. H., Rakowski, W., Fiore, C., Harlow, L. L., Redding, C. A., Rosenbloom, D., \& Rossi, S. R. (1994). Stages 
of change and decisional balance for 12 problem behaviors. Health Psychology, 13, 3946. doi.org/10.1037/0278-6133.13.1.39

Prochaska, J. O., Velicer, W. F., Rossi, J. S., Redding, C. A., Greene, G. W., Rossi, S. R., Sun, X., Fava, J. L., Laforge, R., \& Plummer, B. A. (2004). Multiple risk expert system interventions: Impact of simultaneous stage-matched expert system interventions for smoking, high fat diet and sun exposure in a population of parents. Health Psychology, 23, 503-516. doi: 10.1037/0278-6133.23.5.503

Rakowski, W., Dubé, C. E., Marcus, B. H., Prochaska, J. O., Velicer, W. F., \& Abrams, D. B. (1992). Assessing elements of women's decisions about mammography. Health Psychology, 11(2), 111-118. doi.org/10.1037/0278-6133.11.2.111

Reed, G. R., Velicer, W. F., \& Prochaska, J. O. (1997). What makes a good staging algorithm: Examples from regular exercise. American Journal of Health Promotion, 12, 57-66. doi: $10.4278 / 0890-1171-12.1 .57$

Rohatgi, A. (2015). WebPlotDigitizer user manual version 3.9. Retrieved from https://automeris.io/WebPlotDigitizer/userManual.pdf

Velicer, W. F. (1976). Determining the number of components from the matrix of partial correlations. Psychometrika, 41, 321-327. doi.org/10.1007/BF02293557

Velicer, W. F. (1977). An empirical comparison of the similarity of principal component, image, and factor patterns. Multivariate Behavioral Research, 12, 3-22. doi.org/10.1207/s15327906mbr1201_1

Velicer, W. F., Brick, L. A. D., Fava, J. L., \& Prochaska, J. O. (2013). Testing 40 predictions from the transtheoretical model again, with confidence. Multivariate Behavioral Research, 48, 220-240. doi.org/10.1080/00273171.2012.760439 
Velicer, W. F., \& Colby, S. M. (2005). A comparison of missing-data procedures for ARIMA time-series analysis. Educational and Psychological Measurement, 65, 596-615. doi.org/10.1177/0013164404272502

Velicer, W. F., Cumming, G., Fava, J. L., Rossi, J. S., Prochaska, J. O., \& Johnson, J. L. (2008). Theory testing using quantitative predictions of effect size. Applied Psychology: An International Review, 57, 589-608. doi.org/10.1111/j.1464-0597.2008.00348.x

Velicer, W. F., DiClemente, C. C., Prochaska, J. O., \& Brandenburg, N. (1985). Decisional balance measure for assessing and predicting smoking status. Journal of Personality and Social Psychology, 48, 1279-1289. doi.org/10.1037/0022-3514.48.5.1279

Velicer, W. F., DiClemente, C. C., Rossi, J. S., \& Prochaska, J. O. (1990). Relapse situations and self-efficacy: An integrative model. Addictive Behaviors, 15, 271-283. doi.org/10.1016/0306-4603(90)90070-E

Velicer, W. F., Eaton, C. A., \& Fava, J. L. (2000). Construct explication through factor or component analysis: A review and evaluation of alternative procedures for determining the number of factors or components. In Goffin, R. D., \& Helmes, E. (Eds.), Problems and solutions in human assessment: Honoring Douglas Jackson at seventy (pp. 41-71). Boston: Kluwer.

Velicer, W. F., \& Fava, J. L. (1998). Affects of variable and subject sampling on factor pattern recovery. Psychological Methods, 3, 231-251. doi.org/10.1037/1082-989X.3.2.231

Velicer, W. F., \& Fava, J. L. (2003). Time series analysis. In J. A. Schinka \& W. F. Velicer (Eds.), Handbook of psychology: Research methods in psychology, Vol. 2, pp. 581-606. Hoboken, NJ, US: Wiley \& Sons Inc. http://dx.doi.org/10.1002/0471264385.wei0223 
Velicer, W. F., \& Harrop, J. W. (1983). The reliability and accuracy of time series model identification. Evaluation Review, 7, 551-560.

Velicer, W. F., Hoeppner, B. B., \& Palumbo R. (2012). Idiographic methods: Individual behavior change over time. International Journal of Behavioral Medicine, 19 (Suppl 1), S3.

Velicer, W. F., \& Jackson, D. N. (1990a). Component analysis versus common factor analysis: Some issues in selecting an appropriate procedure. Multivariate Behavioral Research, 25(1), 1-28. doi.org/10.1207/s15327906mbr2501_1

Velicer, W. F., \& Jackson, D. N. (1990b). Component analysis versus common factor analysis: Some further observations. Multivariate Behavioral Research, 25(1), 97-114. doi.org/10.1207/s15327906mbr2501_12

Velicer, W. F., Martin, R. A., \& Collins, L. M. (1996). Section III. Methods for analyzing longitudinal data on relapse: Latent transition analysis for longitudinal data. Addiction, 91(Suppl), S197-S209.

Velicer, W. F., \& McDonald, R. P. (1984). Time series analysis without model identification. Multivariate Behavioral Research, 19, 33-47. doi.org/10.1207/s15327906mbr1901_2

Velicer, W. F., \& McDonald, R. P. (1991). Cross-sectional time series designs: A general transformation approach. Multivariate Behavioral Research, 26, 247-254. doi: $10.1207 / \mathrm{s} 15327906 \mathrm{mbr} 2602 \_3$

Velicer, W. F., Norman, G. J., Fava, J. L., \& Prochaska, J. O. (1999). Testing 40 predictions from the transtheoretical model. Addictive Behaviors, 24, 455-469. doi.org/10.1016/S0306-4603(98)00100-2 
Velicer, W. F., Prochaska, J. O., Bellis, J. M., DiClemente, C. C., Rossi, J. S., Fava, J. L., \& Steiger, J. H. (1993). An expert system intervention for smoking cessation. Addictive Behaviors, 18, 269-290. doi.org/10.1016/0306-4603(93)90029-9

Velicer, W. F, Prochaska, J. O., Fava, J. L., Norman, G. J., \& Redding, C. A. (1998) Smoking cessation and stress management: Applications of the Transtheoretical Model of behavior change. Homeostasis, 38, 216-233.

Velicer, W. F., Prochaska, J. O., Rossi, J. S., \& Snow, M. G. (1992). Assessing outcome in smoking cessation studies. Psychological Bulletin, 111, 23-41. doi.org/10.1037/00332909.111 .1 .23

Velicer, W. F., Redding, C. A., Anatchkova, M. D., Fava, J. L., \& Prochaska, J. O. (2007). Identifying cluster subtypes for the prevention of adolescent smoking acquisition. Addictive Behaviors, 32(2), 228-247. doi.org/10.1016/j.addbeh.2006.03.041

Velicer, W. F., Redding, C. A., Paiva, A. L., Mauriello, L. M., Blissmer, B., Oatley, K., Meier, K. S., Babbin, S. F., McGee, H., Prochaska, J. O., Burditt, C., \& Fernandez, A. C. (2013). multiple behavior interventions to prevent substance abuse and increase energy balance behaviors in middle school students. Translational Behavioral Medicine: Practice, Policy and Research, 3, 82-93. doi: 10.1007/s13142-013-0197-0

Zwick, W. R., \& Velicer, W. F. (1986). Comparison of five rules for determining the number of components to retain. Psychological Bulletin, 99, 432-442. doi.org/10.1037/00332909.99.3.432 